\title{
Correction to: Primary Tumor Location and Outcomes After Cytoreductive Surgery and Intraperitoneal Chemotherapy for Peritoneal Metastases of Colorectal Origin
}

\author{
Mohammad Adileh, MD ${ }^{1}$, Jonathan B. Yuval, MD ${ }^{1}$, Henry S. Walch, MS $^{2,3}$, Walid K. Chatila, MS ${ }^{2,3,4}$, \\ Rona Yaeger, $\mathrm{MD}^{5}$, Julio Garcia-Aguilar, $\mathrm{MD}$, $\mathrm{PhD}^{1}$, Nikolaus Schultz, $\mathrm{PhD}^{2,3,6}$, Philip B. Paty, MD ${ }^{1}$, \\ Andrea Cercek, $\mathrm{MD}^{5}$, and Garrett M. Nash, MD, MPH ${ }^{1}$
}

${ }^{1}$ Colorectal Service, Department of Surgery, Memorial Sloan Kettering Cancer Center, New York, NY; ${ }^{2}$ Human Oncology and Pathogenesis Program, Memorial Sloan Kettering Cancer Center, New York, NY; ${ }^{3}$ Marie-Josée and Henry R. Kravis Center for Molecular Oncology, Memorial Sloan Kettering Cancer Center, New York, NY; ${ }^{4}$ Tri-Institutional Program in Computational Biology and Medicine, New York, NY; ${ }^{5}$ Department of Medicine, Memorial Sloan Kettering Cancer Center, New York, NY; ${ }^{6}$ Department of Epidemiology and Biostatistics, Memorial Sloan Kettering Cancer Center, New York, NY

\section{CORRECTION TO: ANN SURG ONCOL https://doi.org/10.1245/s10434-02 0-08993-7}

In the original article there is a reference missing, in addition to its citations in the text. The reference is as follows:

Kelly KJ, Alsayadnasser M, Vaida F, et al. Does primary tumor side matter in patients with metastatic colon cancer treated with cytoreductive surgery and hyperthermic intraperitoneal chemotherapy? Ann Surg Oncol. 2019;26(5):1421-7.

This reference should have been cited in the following text:
1. Previous studies showing an association between primary tumor sidedness and oncological outcomes following complete cytoreduction surgery and intraperitoneal chemotherapy (CRS/IPC) for pmCRC, while undeniably important, had a few shortcomings:

2. Kelly et al. demonstrated better RFS and OS in leftsided versus right-sided primaries (16 vs 14 months and 69 vs 36 months, respectively, $n=115$ ). Although these differences were not significant on univariable analysis, sidedness was an independent risk factor for both OS and RFS on multivariable analysis.

3. There are some differences between the reports by Kelly et al., Kotha et al., and our study.

The original article can be found online at https://doi.org/10.1245/ s10434-020-08993-7.

(C) Society of Surgical Oncology 2020

Published Online: 1 October 2020

G. M. Nash, MD, MPH

e-mail: nashg@mskcc.org 